Louisiana State University

LSU Digital Commons

\title{
Rape Myths and Hookup Culture: An Exploratory Study of U.S. College Students' Perceptions
}

Timothy T. Reling

Louisiana State University and Agricultural and Mechanical College, trelin2@lsu.edu

Michael S. Barton

Louisiana State University and Agricultural and Mechanical College, mbarto3@lsu.edu

Sarah Anna Becker

Louisiana State University and Agricultural and Mechanical College, sbecker@lsu.edu

Matthew A. Valasik

Louisiana State University and Agricultural and Mechanical College, mvalasik@lsu.edu

Follow this and additional works at: https://digitalcommons.Isu.edu/sociology_pubs

Part of the Gender and Sexuality Commons, and the Social Control, Law, Crime, and Deviance Commons

\section{Recommended Citation}

Reling, T.T., Barton, M.S., Becker, S. et al. Rape Myths and Hookup Culture: An Exploratory Study of U.S. College Students' Perceptions. Sex Roles 78, 501-514 (2018). https://doi.org/10.1007/ s11199-017-0813-4

This Article is brought to you for free and open access by the Department of Sociology at LSU Digital Commons. It has been accepted for inclusion in Faculty Publications by an authorized administrator of LSU Digital Commons. For more information, please contact ir@lsu.edu. 


\title{
Rape Myths and Hookup Culture: An Exploratory Study of U.S. College Students' Perceptions
}

\author{
Timothy T. Reling ${ }^{1} \cdot$ Michael S. Barton $^{1} \cdot$ Sarah Becker $^{1} \cdot$ Matthew A. Valasik $^{1}$
}

Published online: 27 July 2017

(C) Springer Science+Business Media, LLC 2017

\begin{abstract}
The present study provides the first known systematic examination of the association of hookup culture endorsement and rape myth acceptance. Multivariate regression analysis was conducted to test the primary hypothesis that hookup culture endorsement would be the primary predictor of rape myth acceptance levels among a sample of 422 U.S. college students. Findings indicated the existence of a complex relationship in which rape myth acceptance increases or decreases based upon the form of hookup culture endorsement examined. Beliefs that hookups are harmless and elevate social status increased rape myth acceptance, whereas beliefs that hookups express sexual freedom decreased rape myth acceptance. Furthermore, results supported the hypothesis that hookup culture endorsement was the largest predictor of rape myth acceptance. Consistent with previous studies, the predictive power of gender and religiosity in determining levels of rape myth acceptance were shown to be significant. When controlling for levels of hookup culture endorsement, the explanatory power of these variables decreased, and hookup culture endorsement had the largest effect upon rape myth acceptance levels.
\end{abstract}

Keywords Rape myths $\cdot$ Hookup culture $\cdot$ Gender

Electronic supplementary material The online version of this article (doi:10.1007/s11199-017-0813-4) contains supplementary material, which is available to authorized users.

Timothy T. Reling

trelin2@1su.edu

1 Department of Sociology, Louisiana State University, 126 Stubbs Hall, Baton Rouge, LA 70803, USA
The National Sexual Violence Resource Center (2015) estimates one in five women and one in $71 \mathrm{men}$ in the United States will be raped during their lifetime, up to $90 \%$ of these cases will go unreported, and many of the assaults occur in college. To understand such high rates of sexual violence and lack of reporting, researchers have documented the nature of a pervasive rape culture in U.S. society (Buchwald et al. 2005; Martin and Hummer 1989; Phillips 2016; Scully and Marolla 1985). Specifically, numerous studies examined the effect rape myth acceptance has on forming culturally normative attitudes toward sexual assault. Rape myths remain widely accepted throughout the United States (Franiuk et al. 2008; Ward 1995) and influence law enforcement officials making distinctions between "real" rape and other forms of sexual assault (Page 2008; Sleath and Bull 2012). These beliefs can contribute to bystanders, friends, and family members reacting in ways that re-traumatize survivors (Ahrens 2006). Even survivors can internalize rape myths, which increases self-blame and may lead to unreported (Clay-Warner and Burt 2005; Du Mont et al. 2003) or even unacknowledged rape (Wilson and Miller 2016), deepening the psychological injuries associated with victimization.

Efforts to address rape myths and reduce sexual violence by increasing awareness of and education about sexism, sexual assault, and harassment have intensified greatly over the past half century. Much of this work focused on college campuses (Barone et al. 2007; Klaw et al. 2005; Sable et al. 2006; Schwartz et al. 2001). These efforts were met with some success as most people now agree physically injurious rape is wrong and that unwelcome sexual contact should be barred from the workplace (Estrich 1986; Hoffman and Hardyman 1986; Tinkler 2008). Further, serious legal sanctions now exist for sexual assault and harassment (Beichner and Spohn 2012; Dobbin and Kelly 2007; Tinkler 2008). Yet many young Americans still endorse rape myths and dismiss or tolerate 
commonplace forms of assault/aggression like unwanted touching, kissing, or harassment in nightclubs and bars (Becker and Tinkler 2015; Graham et al. 2014; Tinkler et al. 2016) and sexually derogatory public speech (Nielsen 2000, 2006). This raises important analytical and theoretical questions. If awareness of and lack of tolerance for sexual aggression and harassment increased over the past four to five decades, why do young people continue to accept rape myths and minimize common forms of sexual aggression/violence?

The emergence of "hookup culture" offers a potential (if not partial) answer to this question. During the same time that feminist activists, researchers, educators, and practitioners worked to reduce sexual violence and harassment, dating norms across U.S. college campuses changed significantly. Hookup culture, or a social environment that encourages sexual contact free from the binds of commitment or emotional intimacy, came to dominate college social life in the 1990s (Bogle 2008; Wade 2017). Often framed as sex positive and promoting sexual freedom, participation in hookup culture is uneven and less ubiquitous than popular belief suggests (Wade 2017). Nevertheless, it powerfully shapes college social life for participants and non-participants (Currier 2013; Sweeney 2014b; Wade 2017). Like the intimacy norms that predated it, hookup culture disproportionately benefits the privileged (i.e., White, heterosexual, able-bodied, middle/ upper class men) and helps reproduce pre-existing hegemonic power differentials between men and women across race, class, and other status categories (Allison and Risman 2014; Currier 2013; Hamilton and Armstrong 2009; Rupp et al. 2013; Sweeney 2014a; Wilkins 2012). By reinforcing the perceived naturalness of masculine sexual assertion and feminine passivity/gatekeeping, hookup culture perpetuates intersectional patterns in gender inequality.

Rape myths similarly reproduce traditional heteronormative sex scripts that normalize men's sexual aggression. The overlap between rape myth acceptance and hookup culture endorsement has not been examined, but separate studies of the two phenomena reveal overlapping correlates. The current study investigates this overlap using survey data from college students at a large U.S. southern university by exploring the correlations between influences of rape myth acceptance with influences of hookup culture. We examine the extent to which hookup culture endorsement may act as a predictor of rape myth acceptance and how demographic, social, and ideological characteristics mediate the relationship.

\section{Overview of Rape Myths}

Burt (1980) coined the term "rape myth" to refer to false beliefs, stereotypes, and (negative/positive) prejudicial thoughts people hold toward rape survivors/offenders. Burt sought to shift research on rape away from focusing solely on traditional subculture of violence theories to include feminist and social psychological theories on cultural normalization (Sapp et al. 1999). Though several iterations of rape myth measures exist initial research classified beliefs into the categories of victim precipitation, offender intentions, victim pleasure, definitions of rape, false allegations of rape, the trivialization of rape, and the deviance of rape (Burt 1980; Payne et al. 1999). As cultural intolerance for particular forms of sexual assault (e.g., stranger rape) grew and the prevalence of subtle rape myths rose, typologies were reduced to only include categories of victim precipitation, offender intentions, definitions of rape, and false allegations of rape (McMahon and Farmer 2011). Regardless of measurement changes, key elements of victim blaming, offender justification, male aggressiveness, and ambiguity were consistently present in rape myth typologies.

Research on rape myth acceptance proliferated in the latter part of the twentieth century. This body of research demonstrated the intransience of the subset of cultural myths about sexual violence that most closely align with traditional heterosexual sexual scripts. Measures of the trivialization and/or deviance of rape and rapists became less important to include as cultural attitudes toward stranger rape and workplace harassment hardened. Rape myths that reinforce traditional gender beliefs remained important to study. Myths about "good guys" being incapable of sexual offense, culpable victims (i.e., those who violate feminine gender norms or who lie), and those that reinforce the perceived naturalness of men's sexual aggression continue to be widely accepted.

At the same time mainstream attitudes toward rape hardened and subtle rape myths held fast, sexual norms on college campuses were shifting significantly. Emerging in the early 2000s, research on hookup culture provided valuable insight on the current state of collegiate sexual behaviors (Stinson 2010). The primary element of hookup culture is the presence of a wide-range of casual sexual interactions outside of a committed relationship. While participation in hookups was not as widespread as popularly believed (Kimmel 2008; Wade 2017), its norms of avoiding commitment and emotional intimacy in pursuit of superficial, brief sexual encounters deeply influenced college social scenes (Bogle 2008) and young people's identities (Sweeney 2014b) and behaviors (Armstrong et al. 2012; Currier 2013). A limited number of studies measured hookup culture participation and endorsement broadly, using survey data (Armstrong et al. 2012; Aubrey and Smith 2011; England et al. 2007). For example, the recentlydeveloped Endorsement of Hookup Culture Index (EHCI) assesses respondents' perspectives on collegiate hookups using five separate subscales that measure the degree to which respondents perceive hookups as harmless, fun, promoting of social status or a sense of control/power, and supportive of sexual freedom (Aubrey and Smith 2011). 
Most research on participation in and impacts of hookup culture draw on in-depth qualitative interview and/or ethnographic data. These works powerfully illustrate how even though its norms emphasize sexual freedom and ostensibly apply to all young people, hookup culture largely reinforces sexism and racism rather than challenging inequality. It benefits men more than women. Men have disproportionate control over the timing, location, and sexual pleasure of a hookup (Armstrong et al. 2012; Butler 2013; Sweeney 2014a; Wade 2017) and gain status for hooking up (Kimmel 2008; Wade 2017). Benefits for men and women were also unequally distributed by race and class. White and upper middle class and/ or resource-privileged students gain more from hookup culture than did Students of Color or those who are materially disadvantaged (Hamilton and Armstrong 2009; Wilkins 2012). Queer women gain some increased room for stigmafree sexual experimentation by virtue of the norms of hookup culture (Rupp et al. 2013), but the institution remains largely heteronormative.

\section{Hookup Culture and Rape Myth Acceptance}

A review of the literature highlights a common underpinning of hookup culture and commonly-believed rape myths. Both depend on and reproduce the hegemony of traditional heteronormative sexual scripts and gender norms for sexual interaction. Rape myths reinforce the idea that men's sexual appetites are biologically driven, intense, and difficult to control (McMahon and Farmer 2011; Payne et al. 1999). When acquaintance rape happens, these myths increase the likelihood people will sympathetically interpret the offender as a good guy with good intentions who was carried away by his (biologically normal) sex drive. Rape myths simultaneously construct women survivors as poor gatekeepers who did not fight back vigorously enough, gave confusing signals, or "invited" their victimization with what they wore, drank, or consented to prior to the assault (Burt 1980; Ward 1995). When women are assaulted, rape myths contribute to the possibility that a survivor will be stigmatized for not properly living up to feminine norms associated with the traditional heterosexual interaction.

Hookup practices similarly reinforce the normalcy of men as masculine pursuers/ aggressors and women as properly feminine gatekeepers. Men typically control the terms of a hookup (Bogle 2008; Wade 2017), are far more likely to experience sexual pleasure (Armstrong et al. 2012), and are more likely to socially benefit from pursuing a large number of sexual interactions with different women partners (Currier 2013; Wade 2017). They are not exempt from the social risks associated with hooking up with an undesirable partner, but they retain more power than women do to redefine less-thanperfect hookups in ways that elevate their social status
(Currier 2013; Sweeney 2014a). Women, on the other hand, are less likely to initiate a hookup or to control the experience. They benefit less from the interaction and face a higher risk of stigmatization (Currier 2013; Kimmel 2008). Women can gain status from hooking up with a high-status man, but those who gatekeep poorly by saying yes to too many or the wrong type of men risk being labeled undesirable future partners (Currier 2013; Sweeney 2014a).

\section{Contextual Factors}

The literature suggests hookup culture and rape myths both normalize men's use of power in heterosexual interactionwhether it takes the form of initiation and control (in the case of hookups) or the form of aggression (in the case of rape/ sexual assault). That there is contextual overlap between campus sexual assault and campus hookups further underscores the interconnection of these phenomena. Studies found hookup culture carries the risk of participation in unwanted sexual acts and resultant negative emotions (Jozkowski and Peterson 2013; Monto and Carey 2014; Stinson 2010). In addition, college students attribute occurrences of unwanted sexual contact to locations and circumstances where hookup behavior is more common such as dorms, off-campus apartments, and fraternity houses where alcohol is more likely to be present (Ward et al. 1991). Data also suggest rates of sexual assault (Kalof 1993; Ward et al. 1991) and hookups (Glenn and Marquardt 2001; Herold and Mewhinney 1993; Paul and Hayes 2002; Paul et al. 2000) are higher in these spaces and when these factors are present.

\section{Demographic Factors}

If college students are aware that these circumstances and contexts lend themselves to sexual assault, but they are also places where hooking up is common, it supports the idea that rape myth acceptance and hookup culture endorsement might be connected. Although researchers have yet to examine this relationship, separate studies analyzing the demographic correlates of rape myth acceptance and hookup culture endorsement lend credence to the possibility of an association between the two. For example, gender is among the strongest predictors of an individual's willingness to engage in hookup culture, with men participating at significantly higher rates (Bernston and Hoffman 2014; Bogle 2008; England et al. 2007; Freitas 2008; Holman and Sillars 2012). Similarly, although neither gender is impervious to accepting rape myths, men consistently exhibit higher rates of rape myth acceptance (Ching and Burke 1999; Giacopassi and Dull 1986; Gilmartin-Zena 1988). They are more tolerant of rape, hold less empathy toward survivors (Ching and Burke 1999), and 
are more likely to adhere to rape myths, whereas women are more likely to reject them (Gilmartin-Zena 1988; Sapp et al. 1999).

Research examining race yielded mixed results across both bodies of literature, but striking similarities exist. Burt (1980) and Feild (1978) reported Black students were generally more accepting of rape myths than their White counterparts were, but more recent work has identified no such racial difference (Carmody and Washington 2001). Initially, Weinberg and Williams (1988) found that Black individuals endorsed casual sexual encounters at greater rates than White individuals. More recent studies noted a shift in this pattern, providing evidence that White individuals exhibit higher endorsement rates for casual sexual interactions (Owen et al. 2010; Uecker 2008). Many researchers found Asian students exhibit the highest levels of rape myth acceptance (Kennedy and Gorzalka 2002; Lee et al. 2005; Vonderhaar and Carmody 2015). Asian students are also consistently the least likely to endorse or participate in casual sexual behaviors (Cochran et al. 1991; Feldman et al. 1999; Markus and Kitayama 1991; Owen et al. 2010). Most researchers attribute this finding to traditionally rigid gender roles found in Asian culture (Vonderhaar and Carmody 2015).

Greek Life affiliation is also positively correlated with both rape myth acceptance and hookup culture endorsement/participation. Although members of fraternities exhibit the highest levels of rape myth acceptance (Bleecker and Murnen 2005; Foubert et al. 2006; McMahon 2010), sorority members exhibit higher levels of rape myth acceptance, alcohol-related sexual victimization, and physical coercion than the general collegiate student population does (Kalof 1993; McMahon 2010). Many studies also find that fraternity and sorority members participate in hookups at higher rates than do students not involved in Greek life (Bartoli and Clark 2006; Robinson et al. 2004; Scott-Sheldon et al. 2008; Sweeney 2014a). In particular, fraternity members consistently exhibit the highest levels of hookup culture endorsement. Recent work suggests this trend may be shifting as hookup culture becomes more mainstream across college campuses (Bernston and Hoffman 2014).

\section{Ideological Factors}

Few studies empirically examine the impacts of ideological factors on hookup culture and rape myths, but those that do find religiosity significantly influences rape myth acceptance (Freymeyer 1997; Gray et al. 1993; Lonsway and Fitzgerald 1994) and hookup culture endorsement (Burdette et al. 2009; Freitas 2008). Highly religious individuals tend to believe in traditional gender roles and to have little-to-no sympathy for those whose beliefs differ from their own (Finlay 1985; Wylie and Forest 1992). Religiosity significantly influences the likelihood that a person will attribute blame to rape survivors (Gray et al. 1993). Men who place little importance on religion are more likely than are religious men to disagree that women who dress provocatively are to blame for their own victimization (Freymeyer 1997). The opposite is true for religious/nonreligious women - for them, religious belief corresponds with higher levels of rape myth rejection (Freymeyer 1997). Fewer studies examine religiosity and hookup culture endorsement, and findings on the topic are mixed. Some find higher levels of religious service attendance reduces the probability college women will engage in hookups, and religious groups differ in their acceptance of hookup behavior among women (Burdette et al. 2009). Other studies find no evidence of a relationship between religiosity and hookup culture endorsement/ participation (Bernston and Hoffman 2014).

Although not examined with regard to hookup culture endorsement, the influence of intolerant belief systems on rape myth acceptance is present in previous research. Aosved and Long (2006) found an individual's willingness to discriminate based upon age, gender, social class, and religious affiliation are significant predictors of rape myth acceptance. Sexism accounted for the greatest amount of variance (35\%), whereas other intolerant belief systems accounted for much smaller amounts of variance. Furthermore, they noted positive correlations among intolerant belief systems, suggesting that adherence to multiple intolerant belief systems exponentially increases the likelihood of rape myth acceptance. Researchers have yet to examine associations between intolerant belief systems and hookup culture endorsement.

\section{Rape Myths and Hookup Culture: A Conceptual Relationship}

Rape myth acceptance and hookup culture endorsement share many predictors. Although neither gender is impervious, men are more likely to endorse rape myths (Giacopassi and Dull 1986; Gilmartin-Zena 1988; Ching and Burke 1999) and to participate in/support hookup culture (Bernston and Hoffman 2014; Bogle 2008; England et al. 2007; Freitas 2008; Holman and Sillars 2012). Greek life affiliation, particularly fraternity membership, is an important predictor of both (Bartoli and Clark 2006; Bleecker and Murnen 2005; Foubert et al. 2006; McMahon 2010; Robinson et al. 2004; Scott-Sheldon et al. 2008; Sweeney 2014a). The influence of race is debated, but Asian respondents consistently have the highest acceptance of rape myths (Kennedy and Gorzalka 2002; Lee et al. 2005; Vonderhaar and Carmody 2015) and lowest acceptance of hookup culture (Cochran et al. 1991; Feldman et al. 1999; Markus and Kitayama 1991; Owen et al. 2010). Associations between discriminatory belief systems and hookup culture endorsement have yet to be systematically examined, but research finds high levels of religiosity 
significantly influences rape myth acceptance (Freymeyer 1997; Gray et al. 1993; Lonsway and Fitzgerald 1994) and/ or hookup culture endorsement (Burdette et al. 2009; Freitas 2008) in gendered ways.

In addition to sharing these covariates, rape myths and hookup culture share a social-structural foundation. Both depend on and help to reproduce traditional heteronormative sexual scripts and gender norms for sexual interaction. They reinforce the hegemonic perception of men's sexual aggression as normal and women's responsibility to be passive/ feminine gatekeepers (Bogle 2008; McMahon and Farmer 2011; Payne et al. 1999; Wade 2017). In addition, rape and hooking up occur most frequently in the same contextual circumstances: parties occurring in dorms, fraternity houses, and bars (Glenn and Marquardt 2001; Herold and Mewhinney 1993; Kalof 1993; Paul and Hayes 2002; Paul et al. 2000; Ward et al. 1991).

As such, there is an underexplored connection between the acceptance of rape myths and the cultural endorsement of hookups. Though hooking up includes a wide variety of casual sexual behaviors, rape can result from a hookup involving intercourse (or other forms of sexual contact) when consent is not present. If we understand hooking-up includes a broad spectrum of sexual behaviors with hookups resulting in rape or sexual assault if consent is lacking, it is possible to conceptualize hookup culture as a broader set of cultural norms that also encompasses rape culture. Thus, attitudes endorsing both should be similarly structured, with rape myth acceptance being strongly (and positively) influenced by hookup culture endorsement. Because rape myth and hookup culture endorsement both vary strongly by gender, any influence hookup culture has on rape myth acceptance is also likely to be gendered. The current study therefore assesses the association between rape myth acceptance and hookup culture endorsement by testing two hypotheses: (a) hookup culture endorsement will be the largest predictor of rape myth acceptance (Hypothesis 1) and (b) the influence of hookup culture endorsement on rape myth acceptance will differ for U.S. male and female college students (Hypothesis 2).

\section{Method}

\section{Participants}

Participants were 422 undergraduate students at a U.S. southern flagship university, including 299 (71\%) women and 123 (29\%) men. Overall, their average age was 19.1 years-old $(S D=1.15$, range $=18-24), 122(29 \%)$ were affiliated with a Greek organization, and 166 (39\%) were in a relationship. Fully $326(77 \%)$ identified as White, 54 (13\%) were Black, 12 (3\%) identified as Latino/a, 21 (5\%) identified as Asian, and 9 (2\%) identified as other racial groups not listed. Of the 299 women who participated in the study, the average age was 19 years-old $(S D=1.11$, range $=18-24)$, and $223(75 \%)$ women identified as White. Of the remaining women that identified as belonging to a racial minority group, 49 (16\%) identified as Black, 10 (3\%) identified as Latino/a, $11(4 \%)$ were Asian, and $6(2 \%)$ identified as other racial groups not listed. Approximately a third of women in the sample $(n=99$, $33 \%$ ) were affiliated with a Greek organization and $129(43 \%)$ indicated they were in a relationship. Similarly, of the 123 men who participated in the study, their average age was 19.37 years-old $(S D=1.20$, range $=18-23)$, and $103(84 \%)$ men identified as White. Of the remaining men, $5(4 \%)$ identified as Black, 2 (2\%) were Latino/a, $10(8 \%)$ were Asian, and $3(2 \%)$ identified as other racial groups not listed. About a third of the men $(n=37,30.1 \%)$ indicated they were in a relationship at the time of the study, and 23 (19\%) were affiliated with a Greek organization. Statistically significant gender differences were found for age, $t(213.14)=3.00, p=.003$, relationship status, $\chi^{2}(1)=6.23, p=.013$, Greek life affiliation, $\chi^{2}(1)=8.81, p=.003$, proportion of White students, $\chi^{2}(1)=4.16, p=.041$, and proportion of Black students, $\chi^{2}(1)=11.86, p<.001$.

\section{Procedure and Measures}

We recruited students enrolled in introductory sociology courses during the Spring 2016 semester to minimize the likelihood participants had taken courses including rape education because previous research found rape education decreased rape myth acceptance (Hertzog and Yeilding 2009; McMahon 2010). Gender, age, and racial distributions of the sample relatively matched the undergraduate population (LSU Division of Strategic Communications 2015). The online survey was constructed and administered to participants via Moodle, a learning management system used by many instructors at the university. Consistent with our IRB approval, extra credit was offered for participation in this study at the discretion of course instructors. All participants had the option to decline participation in the study. To mitigate psychological harm, participants were administered a list of local mental health services to contact should the need have arisen.

The survey, titled the Student Perception Survey, collected demographic information in addition to including items originally developed for the Illinois Rape Myth Acceptance-Short Form scale (McMahon and Farmer 2011), the Male Rape Myths scale (Melanson 1999), the Endorsement of Hookup Culture Index (Aubrey and Smith 2011), and the SelfAscribed Spirituality and Religiosity Variables scale (SASRV; Zullig et al. 2006), in this order. The Illinois Rape Myth Acceptance-Short Form scale and the Male Rape Myth scale measured heterosexual and homosexual rape myth acceptance. The Endorsement of Hookup Culture Index was utilized as a measure of hookup culture endorsement. The 
Self-Ascribed Spirituality and Religiosity Variables scale measured the influence of ideological factors; demographic information was collected to assess the influences of race, gender, social relations, and family structure.

\section{Modified Illinois Rape Myth Acceptance-Short Form Scale}

The modified form of the IRMA-SF (McMahon and Farmer 2011) measures respondents' beliefs about rape survivors and offenders, as well as the circumstances which constitute rape, across the original 22 items of the four IRMA-SF subscales: She Asked for It (e.g., "When girls go to parties wearing slutty clothes, they are asking for trouble"), He Didn't Mean to (e.g., "Guys don't usually intend to force sex on a girl, but sometimes they get too sexually carried away"), It Wasn't Really Rape (e.g. If a girl doesn't say 'no' she can't claim rape”), and She Lied (e.g. "Girls who are caught cheating on their boyfriends sometimes claim it was rape"). To adjust for heteronormativity, the 22-item Male Rape Myth scale (Melanson 1999) was also treated as a subscale (e.g. "A man who allows himself to be raped by another man is probably homosexual"). Respondents rated each of the 44 items on a 5point scale ranging from 1 (Strongly Disagree) to 5 (Strongly Agree). Responses across items on each of the five subscales were additive so that higher scores indicated stronger beliefs on that particular subscale, and the subscales themselves were additive so that higher scores indicated stronger rape myth acceptance in general.

Alphas from the original studies demonstrated strong internal reliability for the overall measure ( $\alpha=.89$ for IRMA-SF; $\alpha=.90$ for MRMS) as well as acceptable reliability for each subscale (alphas range from .64 to .80). The current study also demonstrated strong internal reliability for the modified overall measure ( $\alpha=.95)$, as well as for each subscale: She Asked for It $(\alpha=.82)$, He Didn't Mean to $(\alpha=.75)$, She Lied $(\alpha=.85)$, It Wasn't Really Rape $(\alpha=.88)$, and Male Rape Myths $(\alpha=.93)$. The construct validity and discriminant validity of the IRMA-SF and MRMS has been established in previous research (McMahon and Farmer 2011; Melanson 1999).

\section{Endorsement of Hookup Culture Index}

The EHCI (Aubrey and Smith 2011) assesses respondents' perspectives on collegiate hookups in general across five separate subscales: Harmless (e.g., "Hooking up is not a big deal"), Fun (e.g., "I hook up to have a good time"), Status (e.g., "Hooking up is a way for me to make a name for myself"), Control (e.g., "I feel powerful during a hookup"), and Sexual Freedom (e.g., "Hooking up allows me to be sexually adventurous"). Each subscale was composed of four such questions, and respondents rated each of the 20 items on a 5-point scale ranging from 1 (Strongly Disagree) to 5 (Strongly Agree).
Responses across items on each of the five subscales were additive so that higher scores indicated stronger beliefs on that particular subscale.

Alphas from the original study demonstrated strong internal reliability for the overall measure $(\alpha=.91)$, as well as for each subscale: Harmless $(\alpha=.84)$, Fun $(\alpha=.88)$, Status $(\alpha=.90)$, Control $(\alpha=.79)$, and Sexual Freedom $(\alpha=.86)$. Analogously, the current study also demonstrated strong internal reliability for the overall measure $(\alpha=.93)$, as well as for each subscale: Harmless $(\alpha=.92)$, Fun $(\alpha=.85)$, Status $(\alpha=.90)$, Control $(\alpha=.77)$, and Sexual Freedom $(\alpha=.90)$. The construct validity and discriminant validity of the EHCI has been established in previous research (Aubrey and Smith 2011).

\section{Control variables}

The selection of control variables was guided by previous research and includes respondents' gender (Ching and Burke 1999; Gilmartin-Zena 1988) and Greek organization affiliation (Bleecker and Murnen 2005; Foubert et al. 2006; Kalof 1993; McMahon 2010). Relationship status was controlled to assess the influence of intimate interpersonal commitment on rape myth acceptance because individuals in committed relationships may be less endorsing of hookup culture. Spirituality and religiosity were included as control variables to assess the influence of ideological factors and were measured using the 6-item Self-Ascribed Spirituality and Religiosity Variables scales (SASRV; Zullig et al. 2006). The SASRV assesses respondents' perceptions about their personal relationships with religion through two subscales: Spirituality (i.e. "I am very spiritual"; 3 items) and Religiosity (i.e. "How often did you typically attend religious services in the past year?"; 3 items). In congruence with previous research, spirituality was conceptualized as "one's search for the sacred that occurs internally and is pursued through seeking a relationship with whatever one holds as sacred" (Hyman and Handal 2006, p.279). Religiosity was conceptualized as "the rituals and organization traditions that one practices in a group setting and that guides one's behavior" (p. 278). Responses across items were summed so that higher scores indicated stronger beliefs on that particular subscale. Alphas from the original study demonstrated strong internal consistency for each subscale: Spirituality $(\alpha=.88)$ and Religiosity $(\alpha=.91)$. Similarly, the current study demonstrated high levels of internal reliability for the overall measure $(\alpha=.93)$, as well as the Spirituality $(\alpha=.88)$ and Religiosity $(\alpha=.92)$ subscales.

\section{Analysis Strategy}

Data collection for our study was approved by the Louisiana State University Institutional Review Board. The current study assesses the association of rape myth acceptance with hookup culture endorsement through a series of ordinary least 
squares regression models. Model 1 examines the associations of rape myth acceptance with control variables (age, gender, relationship status, Greek affiliation, spirituality, and religiosity) to assess the generalizability of the current study with previous research. Model 2 examines the relationship between rape myth acceptance with control variables (age, gender, relationship status, Greek affiliation, spirituality, and religiosity) while controlling for specific forms of hookup culture endorsement. Subsequent analyses examined the associations of hookup culture endorsement with specific forms of rape myth acceptance, but results were identical to those of general rape myth acceptance. (These supplemental results are available in an online supplement.)

\section{Results}

\section{Preliminary Analyses}

Table 1 presents descriptive statistics and bivariate correlations for the variables included in the analyses. Separate descriptive statistics are presented for the full and genderspecific samples to match with the multivariate regressions, and bivariate correlations with the IRMA were assessed to determine the importance of the independent variables for gender-specific samples. We first explored gender differences (a) in spirituality and religiosity, (b) across the five subscales regarding endorsement of hook-up culture (EHCI), and (c) in rape myth acceptance, controlling for age, relationship status, and Greek affiliation in each. The first MANCOVA revealed a multivariate gender main effect, $F(2,416)=4.56, p=.011$, $\eta \mathrm{p}^{2}=.02$, that was accounted for by a significant univariate effect for spirituality, $F(1,420)=8.75, p=.003, \eta p^{2}=.02$. Spirituality was significantly associated with increased acceptance of rape myths among women and men (see Table 1).

Our second MANCOVA revealed a significant main effect for gender, $F(5,413)=32.18, p<.001, \eta p^{2}=.28$, that was accounted for by beliefs that hookups are harmless, $F(1$, $417)=20.71, p<.001, \eta p^{2}=.05$; fun, $F(1,417)=31.81$, $p<.001, \eta \mathrm{p}^{2}=.07$; elevate social status, $F(1,417)=146.67$, $p<.001, \eta \mathrm{p}^{2}=.26$; and promote sexual freedom, $F(1$, $417)=27.36, p<.001, \eta p^{2}=.06$. Finally, our ANCOVA indicated large and significant differences in rape myth acceptance among men and women, $F(1,417)=47.22, p<.001$, $\eta \mathrm{p}^{2}=.10$, Cohen's $d=.72$, in that women were on average less accepting of rape myths than men were (see Table 1).

Turning to the correlations among our variables, both spirituality and religiosity were significantly associated with increased acceptance of rape myths among women and men (see Table 1). The correlations of the EHCI measures with rape myth acceptance also yielded a few results of note. The correlations for the subscales of harmless, fun, and status with rape myth acceptance were positive and significant for both

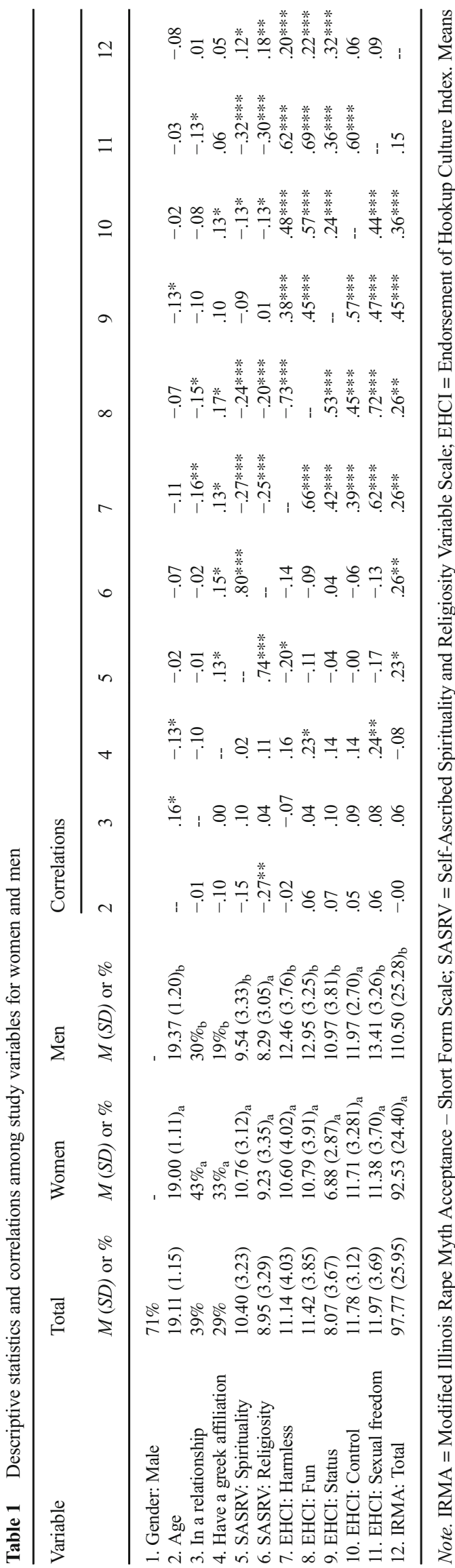


women and men. The correlation of control with rape myth acceptance was positive and significant for men, but not for women. The correlation of sexual freedom with rape myth acceptance was not significant for either gender. Together, these results show at least partial support for the findings of previous research that the predictors of rape myth acceptance differ for women and men, highlighting the importance of conducting gender-specific multivariate analyses.

\section{Hypothesis 1: Predictors of Rape Myths}

Table 2 presents results of the OLS regression analyses that tested Hypothesis 1, which stated hookup culture endorsement will be the largest predictor of rape myth acceptance. Multicollinearity was assessed by reviewing bivariate correlations (see Table 1) and the variance inflation factor results for each regression model. The average variation inflation value across all models was 1.76 , with no variable in any model featuring a variance inflation factor greater than 3.00. Model 1 examined the associations of the control variables with rape myth acceptance to establish a baseline. The Adjusted $R^{2}$ indicated that $12.5 \%$ of the variation within the model was explained by control variables alone. Of the control variables, gender featured the strongest association $(\beta=-.35, t=-7.27$, $p<.001)$ with rape myth acceptance. This finding indicates that female students were less likely to accept rape myths than male students were, even after controlling for other factors. The results in the baseline model also indicated that

Table 2 Endorsement of hookup culture and control variables as predictors of overall rape myth acceptance

\begin{tabular}{|c|c|c|c|c|}
\hline \multirow[t]{2}{*}{ Predictors } & \multicolumn{2}{|c|}{ Model 1: Full sample } & \multicolumn{2}{|c|}{ Model 2: Full sample } \\
\hline & $\mathrm{b}$ & $\beta$ & $\mathrm{b}$ & $\beta$ \\
\hline Constant & 115.17 & - & 63.21 & - \\
\hline Age & -.87 & -.04 & -.36 & -.02 \\
\hline Gender: Male & $-19.68 * * *$ & -.35 & $-8.13 * *$ & -.14 \\
\hline In a relationship & 1.23 & .02 & 2.56 & .05 \\
\hline Greek affiliation & -.99 & -.02 & -4.48 & -.08 \\
\hline SASRV: Spirituality & -.12 & -.02 & .61 & .08 \\
\hline SASRV: Religiosity & $1.60 * *$ & .20 & $1.27 *$ & .16 \\
\hline EHCI: Harmless & & & $.99 *$ & .15 \\
\hline EHCI: Fun & & & .89 & .13 \\
\hline EHCI: Status & & & $2.38 * * *$ & .34 \\
\hline EHCI: Control & & & .04 & .01 \\
\hline EHCI: Sexual freedom & & & $-.93 *$ & -.13 \\
\hline Adjusted $R^{2}$ & \multicolumn{2}{|l|}{.13} & \multicolumn{2}{|c|}{.27} \\
\hline
\end{tabular}

Note. SASRV = Self-Ascribed Spirituality and Religiosity Variables scale; EHCI = Endorsement of Hookup Culture Index

$* p<.05 . * * p<.01 . * * * p<.001$ respondents who were more religious were more likely to accept rape myths ( $\beta=.20, t=2.73, p=.007)$. None of the other control variables was significantly associated with rape myth acceptance.

Results in Model 2 support Hypothesis 1 because three of the five measures of hookup culture endorsement were significant predictors of rape myth acceptance. Even when controlling for demographic, social, and ideological characteristics of respondents, the belief that hookups elevate an individual's social status was the largest predictor of rape myth acceptance. The Adjusted $R^{2}$ indicated that $27.0 \%$ of the variation within the model was explained by control variables, spirituality/religiosity, and hookup culture endorsement measures. Furthermore, the change in Adjusted $R^{2}$ indicates that the measures of hookup culture endorsement predict $14.5 \%$ of the variation within the model above and beyond that which was predicted by control variables.

Specifically, three of the five measures of hookup culture endorsement were significant predictors of rape myth acceptance. Harmless $(\beta=.15, t=2.40, p=.017)$ and status $(\beta=.34, t=6.02, p<.001)$ were positively associated with acceptance of rape myths whereas sexual freedom $(\beta=-.13$, $t=-2.03, p=.043$ ) was negatively associated with rape myth acceptance (see Table 2). The results in Model 2 also indicate gender was an important predictor of rape myth acceptance, with female students being less accepting of rape myths than were male students $(\beta=-.14, t=-2.81, p=.005)$. Additionally, students who reported greater religiosity were more likely to report acceptance of rape myths $(\beta=-.16$, $t=2.34, p=.020$ ).

Comparison of the results in Models 1 and 2 (see Table 2) indicate that the incorporation of hookup culture endorsement measures substantially increased explained variability and resulted in substantial differences between coefficients for the control variables. To explore whether these differences were statistically significant, a comparison of regression coefficients was performed using the technique described by Clogg et al. (1995). In assessing the extent to which the inclusion of predictor variables, $Z_{i}$, exert influence upon the coefficients of control variables, $X_{i}$, this test acts as a preliminary indicator of the moderating influences of hookup culture endorsement upon the relationship of the control variables and rape myth acceptance. Results in Table 3 indicate that the changes in the coefficients for gender, Greek Affiliation, spirituality, and religiosity between Models 1 and 2 were significant. As such, evidence suggests hookup culture endorsement influences the relationship between rape myth acceptance with the control variables in important ways. In support of Hypothesis 1, analysis of the full sample indicated students who believed hookups were harmless and elevate social status were more likely to accept rape myths, whereas students who believed hookups provide sexual freedom were less accepting of rape myths. 
Table 3 A comparison of two regression models predicting rape myth acceptance

\begin{tabular}{llll}
\hline & $\begin{array}{l}\text { Model } 1 \\
b(S D)\end{array}$ & $\begin{array}{l}\text { Model } 2 \\
b(S D)\end{array}$ & $\begin{array}{l}\text { Change in } \\
\text { Coefficient }\end{array}$ \\
\hline Intercept & $115.17(21.23)$ & $63.21(20.60)$ & $51.96(3.55)$ \\
$X_{1}:$ Age & $-.87(1.06)$ & $-.36(.98)$ & $-.52(.27)$ \\
$X_{2}:$ Gender: Male & $-19.68(2.71)$ & $-8.13(2.89)$ & $-11.55(1.29)$ \\
$X_{3}:$ In a relationship & $1.23(2.46)$ & $2.56(2.26)$ & $-1.33(.63)$ \\
$X_{4}:$ Greek affiliation & $-.99(2.68)$ & $-4.48(2.50)$ & $3.49(.54)$ \\
$X_{5}:$ SASRV: Spirituality & $-.12(.60)$ & $.61(.55)$ & $-.73(.13)$ \\
& & $1.27(.55)$ & $.32(.13)$ \\
$Z_{1}:$ EHCI: Harmless & & $.99(.41)$ & $-8.95^{* * *}$ \\
$Z_{2}:$ EHCI: Fun & & $.89(.49)$ & -2.13 \\
$Z_{3}:$ EHCI: Status & & $2.38(.40)$ & $2.51^{*}$ \\
$Z_{4}:$ EHCI: Control & & $.04(.44)$ & \\
$Z_{5}:$ EHCI: Sexual freedom & & $-.93(.46)$ & \\
$\sigma$ & 24.27 & 22.17 & .27 \\
Adjusted $R^{2}$ & .13 & & \\
\hline
\end{tabular}

Note. SASRV = Self-Ascribed Spirituality and Religiosity Variables scale; EHCI $=$ Endorsement of Hookup Culture Index. $X_{i}$ variables are control variables for which statistically significant shifts of coefficients are being determined. $Z_{I}$ variables are additional control variables which demonstrate a possible moderating influence on $X_{i}$ variables. $\sigma=$ Regression Error Variance for Model. Change in Coefficients calculated by $d_{k}=b^{*}-b$. Test statistic calculated by $t=d_{k} / s\left(d_{k}\right)$

$* p<.05 . * * p<.01 . * * * p<.001$

\section{Hypothesis 2: Gender Comparisons Across Models}

Hypothesis 2 predicted that the importance of hookup culture for rape myth acceptance would differ for male and female students. Results presented in Table 4 do not support this

Table 4 Control variables and endorsement of hookup culture as predictors of total rape myth acceptance separately for women and men

\begin{tabular}{|c|c|c|c|c|}
\hline \multirow[t]{2}{*}{ Predictors } & \multicolumn{2}{|c|}{ Model 3: Women only } & \multicolumn{2}{|c|}{ Model 4: Men only } \\
\hline & $\mathrm{b}$ & $\beta$ & $\mathrm{b}$ & $\beta$ \\
\hline Constant & 68.78 & - & 27.44 & - \\
\hline Age & -.77 & -.04 & .68 & .03 \\
\hline In a relationship & 3.32 & .07 & .69 & .01 \\
\hline Greek affiliation & -2.01 & -.04 & $-11.83^{*}$ & -.18 \\
\hline SASRV: Spirituality & .29 & .04 & .81 & .11 \\
\hline SASRV: Religiosity & $1.36^{*}$ & .19 & 1.80 & .22 \\
\hline EHCI: Harmless & .84 & .14 & 1.30 & .19 \\
\hline EHCI: Fun & 1.11 & .18 & .47 & .06 \\
\hline EHCI: Status & $2.10 * * *$ & .25 & $2.26^{* *}$ & .34 \\
\hline EHCI: Control & -.54 & -.07 & 1.63 & .17 \\
\hline EHCI: Sexual freedom & -.61 & -.09 & -1.28 & -.17 \\
\hline Adjusted $R^{2}$ & \multicolumn{2}{|c|}{.15} & \multicolumn{2}{|l|}{.30} \\
\hline
\end{tabular}

Note. SASRV $=$ Self-Ascribed Spirituality and Religiosity Variables scale; $\mathrm{EHCI}=$ Endorsement of Hookup Culture Index

$* p<.05 . * * p<.01 . * * * p<.001$ hypothesis. Model 3 regressed rape myth acceptance on the control variables and the measures of hookup culture endorsement using only the students who identified as female, whereas the sample for Model 4 included only students who identified as male. Results show that status was a significant predictor of rape myth acceptance for both female students $(\beta=.25, t=3.99, p<.001)$ and male $(\beta=.34, t=3.32$, $p=.001)$ students. This pattern indicates that students, regardless of their gender, who reported hookups helped to improve social status were more likely to report acceptance of rape myths. The gender-specific analyses also identified differences among the control variables with religiosity being positively associated with rape myth acceptance only for female students $(\beta=.19, t=2.04, p=.042)$ and Greek Affiliation being negatively associated with rape myth acceptance only for male students ( $\beta=-.18, t=-2.30, p=.023)$. As a result, Hypothesis 2 was not supported because results of the genderspecific analyses indicated students who believed hookups were positively associated with status were more likely to accept rape myths regardless of gender.

\section{Discussion}

The present study uniquely contributes to research on rape myth acceptance by systematically assessing the strength and directionality of the association between rape myth acceptance and hookup culture endorsement. Results indicate that 
female students in the United States were less likely to report believing rape myths than male students were, and more religious students were more likely to accept rape myths. These findings corroborate prior research that demonstrated women were less accepting of rape myths (Ching and Burke 1999; Gilmartin-Zena 1988) and hookup culture (Bernston and Hoffman 2014; Bogle 2008; England et al. 2007; Freitas 2008; Holman and Sillars 2012) than men were and that religiosity was associated with higher levels of rape myth endorsement, especially among women (Freymeyer 1997; Gray et al. 1993). In support of Hypothesis 1, the results showed three of the five measures of hookup culture endorsement were significant predictors of rape myth acceptance. Variation in the direction of coefficients among the subscales, however, shows the relationship of hookup culture and rape myth acceptance is more complex than previously believed. Individuals were more accepting of rape myths if they ascribed to the belief that hookups are harmless or that they elevate social status. Conversely, individuals who believed hookups were an expression of sexual freedom were less accepting of rape myths.

Findings from the gender-specific regression model do not support Hypothesis 2. Instead, they suggest the effect of hookup culture on rape myth acceptance is similar for men and women. For both, the belief that hookups elevate status demonstrates a positive association and functions as the largest predictor of rape myth acceptance. The gender-specific analyses identified some differences in the importance of control variables, with Greek-affiliated men reporting lower overall rape myth acceptance and more religious women reporting higher levels of rape myth acceptance. Greek life affiliation correlated with lower rape myth acceptance among men, even though the opposite has consistently been found in previous research (Bleecker and Murnen 2005; Foubert et al. 2006; McMahon 2010). The association in our study could be linked to Greek student populations being targeted for rape education programming, which decreases rape myth acceptance (Hertzog and Yeilding 2009; McMahon 2010). If university administrators acted on recommendations to provide rape education to Greek student populations (Bleecker and Murnen 2005; Foubert 2000; Foubert and Newberry 2006; Foubert et al. 2006; Kalof 1993; Martin and Hummer 1989; McMahon 2010), it could explain this finding.

The results of our study also highlighted the complex relationship of hookup culture for rape myth acceptance, which lends credence to a conceptualization where rape culture occupies a unique space within the broader context of hookup culture. Beliefs that hookups are harmless and elevate social status are associated with higher levels of rape myth acceptance among students, but believing that hookups promote sexual freedom is associated with lower levels of rape myth acceptance. A possible explanation for this is that positive associations are found primarily in beliefs that reflect adherence to traditional gender roles and hegemonic masculinity, as scholars argue hookup culture does (Currier 2013; Kalish 2013; Stinson 2010), whereas negative associations are found for beliefs that reject traditional gender roles and seem to promote female empowerment. It is also possible students who believe brief non-emotional sexual interactions are evidence of sexual freedom have been exposed to feminist scholarship and/or logic relevant to women's empowerment/choice, sexuality, and risk. Exposure to that scholarship and type of education could also decrease the likelihood that they would accept popular rape myths (Flores and Hartlaub 1998).

Status, in particular, stood out as the component of hookup culture that most strongly influences rape myth acceptance, with results in the full and gender-specific models indicating status was positively associated with rape myth acceptance. This aspect of hookup culture probably best captures the gender inequity embedded in mainstream sexual scripts/norms. Researchers have consistently documented a double standard for men and women whereby sexual expertise and experience elevates men's status and decreases women's (Butler 2013; Currier 2013; Kalish 2013; Kimmel 2008). One might therefore expect people who endorse widely accepted beliefs like rape mythology would also express beliefs that echo mainstream ideas about the sexual double standard. That was not the case. Instead, both women and men who say hooking up increases their social status were more likely to believe rape myths.

This finding reinforces qualitative research that reported hooking up is more fraught with and carries a higher risk of stigmatization for women (Kimmel 2008), well-chosen hookups can elevate status regardless of gender (Currier 2013; Sweeney 2014a; Wade 2017) and some level of participation in hookup culture is a prerequisite for inclusion in the college party scene (Wade 2017). This finding also highlights the connection between the norms of hookup culture and rape mythology. Students who report believing that hookups elevate social status are likely to be most closely aligned with the campus partying scene that encapsulates the majority of hooking up practices. Previous research suggests that participants in the campus partying scene(s) are most likely to align their behaviors and identify with hookup culture (Kimmel 2008; Sweeney 2014a, b; Wade 2017). In recognition of a social order where men gain status in their homosocial networks for hooking up and women can gain status by participating carefully in hookup culture (Currier 2013; Sweeney 2014a), it is likely that people who report hooking up elevates status are likely more closely aligned with the college partying scene. Because that scene normalizes men's routine displays of aggression in heterosexual interaction (Armstrong et al. 2006; Becker and Tinkler 2015; Ronen 2010; Tinkler et al. 2016), it is unsurprising that support for and participation in it would be correlated with believing rape myths that downplay men's sexual aggression and stigmatize women survivors for 
failing to live up to feminine norms for heterosexual interaction.

\section{Limitations and Future Research Directions}

Most of our study's limitations are due to its exploratory nature. First, the results of our study may not be generalizable due to the use of a non-random sampling technique. Second, the sample was representative of the university's undergraduate population in terms of race, but women were oversampled (52.0\% of the general undergraduate population compared to $70.9 \%$ of respondents). Third, because this study collected self-reported data on perceptions regarding a sensitive subject, it is important to recognize the possibility of social desirability bias in responses, especially among students who may have been targeted for rape awareness education or who participate in organizations widely perceived as participating in rape culture. To the extent possible, social desirability was controlled by assuring that participants' responses would be completely anonymous, but the concern remains important to consider. Fourth, the results suggest particular aspects of hookup culture mediate the relationship between model control variables and rape myth acceptance. A full exploration of this mediation was beyond the scope of the current analysis, but should be further assessed.

Future research should expand on our study by using a more intersectional analytical strategy. Our study looked at a predominantly White sample of students because the limited number of Students of Color in our sample (96 total, of whom only 20 were men) prevented a fully intersectional analysis strategy. In exploring the intersection(s) of race, gender, and sexuality, for example, researchers would be better able to quantitatively examine how marginalized groups navigate collegiate hookup culture, providing support to studies that have explored this subject qualitatively (England et al. 2007; Wade 2017). Additionally, an intersectional approach would allow for better examination of the associations for hookup culture and rape myth acceptance because our study established that these associations do differ by gender. Finally, future studies should examine the mediating influence of hookup culture endorsement upon rape myth acceptance as a way of establishing a causal order.

\section{Practice Implications}

Our study has shown that hookup culture endorsement is a leading predictor of rape myth acceptance. This knowledge could be utilized by colleges and universities to target their rape prevention training - specifically, to encourage them to move away from the primary rape education method of reducing rape myth acceptance and toward addressing the broader issue of campus hookup culture. Educational programs could incorporate critical discussion of the norms of hookup culture and the potential negative/positive impact they have on sexual health and social life for people of all genders (Wade 2017). In addition, including items that measure hookup culture endorsement on campus climate surveys would allow colleges and universities to identify individuals with the greatest need for rape education. Colleges and universities that currently offer rape education programs in the forms of sexual education, open-forums, and bystander intervention training would benefit from such knowledge because it has been shown that these programs have longstanding effects (Flores and Hartlaub 1998; Foubert 2000; Foubert and Newberry 2006; Foubert et al. 2006) - effects our findings suggest could be amplified by including conversation(s) about sexual norms and health on campus.

\section{Conclusion}

The present study sets the ground for a conceptual framework that situates rape myth acceptance on a spectrum of a broader culture of sexual interaction norms on college campuses. Specifically, it suggests rape myth acceptance is a part of campus hookup culture. Findings indicate hookup culture endorsement could be among the most significant predictors of rape myth acceptance among college students in the United States. As such, our study supports findings from qualitative studies of hookup culture, which capture the ways it perpetuates traditional gender roles (Currier 2013), reinforces the naturalness of male aggression (Kalish 2013; Stinson 2010), legitimizes the use of deception/aggression to gain consent (Jozkowski and Peterson 2013), and reproduces pre-existing gendered power relations in ways that intersect with race, class, gender, sexuality, and other aspects of social status (Hamilton and Armstrong 2009; Reid et al. 2011; Rupp et al. 2013; Wilkins 2012). By demonstrating the closeness of rape mythology and beliefs supportive of hookup culture, our study pushes for broader conceptions of sexual normsconceptions that allow scholars to carefully interrogate the line(s) between consensual, desirable heterosexual interactions and the (male) aggression and (female) victimization that they potentially normalize.

Compliance with Ethical Standards There were no potential conflicts of interest regarding this research. All subjects had the option to decline participation in the study. To mitigate psychological harm, subjects were administered a list of local mental health services to contact should the need have arisen.

\section{References}

Ahrens, C. E. (2006). Being silenced: The impact of negative social reactions on the disclosure of rape. American Journal of Community Psychology, 38, 31-34. doi:10.1177/088626001016012002. 
Allison, R., \& Risman, B. J. (2014). "It goes hand in hand with the parties": Race, class, and residence in college student negotiations of hooking up. Sociological Perspectives, 57, 102-123. doi:10. $1177 / 0731121413516608$.

Aosved, A. C., \& Long, P. J. (2006). Co-occurrence of rape myth acceptance, sexism, racism, homophobia, ageism, classism, and religious intolerance. Sex Roles, 55, 481-492. doi:10.1007/s11199-006-91014.

Armstrong, E. A., Hamilton, L., \& Sweeney, B. (2006). Sexual assault on campus: A multilevel, integrative approach to party rape. Social Problems, 53, 483-499. doi:10.1525/sp.2006.53.4.483.

Armstrong, E. A., England, P., \& Fogarty, A. C. (2012). Accounting for women's orgasm and sexual enjoyment in college hookups and relationships. American Sociological Review, 77, 435-462. doi:10. $1177 / 0003122412445802$.

Aubrey, J., \& Smith, S. (2011). Development and validation of the endorsement of the Hookup Culture Index. Journal of Sex Research, 50, 435-448. doi:10.1080/00224499.2011.637246.

Barone, R. P., Wolgemuth, J. R., \& Linder, C. (2007). Preventing sexual assault through engaging college men. Journal of College Student Development, 48, 585-594. doi:10.1353/csd.2007.0045.

Bartoli, A. M., \& Clark, M. D. (2006). The dating game: Similarities and differences in dating scripts among college students. Sexuality and Culture, 10, 54-80. doi:10.1007/s12119-006-1026-0.

Becker, S., \& Tinkler, J. (2015). "Me getting plastered and her provoking my eyes": Young people's attribution of blame for sexual aggression in public drinking spaces. Feminist Criminology, 10, 235-258. doi: $10.1177 / 1557085114541142$.

Beichner, D., \& Spohn, C. (2012). Modeling the effects of victim behavior and moral character on prosecutors' charging decisions in sexual assault case. Violence and Victims, 27, 3-24. doi:10.1891/08866708.27.1.3.

Bernston, M. A., \& Hoffman, K. L. (2014). College as context: Influences on interpersonal sexuality scripts. Sexuality and Culture, 18, 149165. doi:10.1007/s12119-013-9180-7.

Bleecker, E. T., \& Murnen, S. K. (2005). Fraternity membership, the display of degrading sexual images of women, and rape myth acceptance. Sex Roles, 53, 487-493. doi:10.1007/s11199-005-7136-6.

Bogle, K. A. (2008). Hooking up: Sex, dating, and relationships on campus. New York: New York University Press.

Buchwald, E., Fletcher, P., \& Roth, M. (Eds.). (2005). Transforming a rape culture (2nd ed.). Minneapolis: Milkweed Editions.

Burdette, A. M., Ellison, C. G., Hill, T. D., \& Glenn, N. (2009). Hooking up at college: Does religion make a difference? Journal for the Scientific Study of Religion, 48, 535-551.

Burt, M. (1980). Cultural myths and support for rape. Journal of Personality and Social Psychology, 38, 217-230. doi:10.1037// 0022-3514.38.2.217.

Butler, J. (2013). Sexual subjects: Hooking up in the age of postfeminism (Unpublished doctoral dissertation). Department of Sociology, University of Southern California, Los Angeles, CA.

Carmody, D. C., \& Washington, L. M. (2001). Rape myth acceptance among college women: The impact of race and prior victimization. Journal of Interpersonal Violence, 16, 424-436. doi:10.1177/ 088626001016005003.

Ching, C. L., \& Burke, S. (1999). An assessment of college students' attitudes and empathy toward rape. College Student Journal, 33(4), 573-583.

Clay-Warner, J., \& Burt, C. H. (2005). Rape reporting after reforms have times really changed? Violence Against Women, 11, 150-176. doi: 10.1177/1077801204271566.

Clogg, C. C., Petkova, E., \& Haritou, A. (1995). Statistical methods for comparing regression coefficients between models. American Journal of Sociology, 100, 1261-1293. doi:10.1086/230638.

Cochran, S. D., Mays, V. M., \& Leung, L. (1991). Sexual practices of heterosexual Asian-American adults: Implications for risk of HIV infection. Archives of Sexual Behavior, 20, 381-391. doi:10.1007/ BF01542618.

Currier, D. M. (2013). Strategic ambiguity protecting emphasized femininity and hegemonic masculinity. Gender and Society, 27, 704727. doi:10.1177/0891243213493960.

Dobbin, F., \& Kelly, E. L. (2007). How to stop harassment: Professional construction of legal compliance in organizations. American Journal of Sociology, 112, 1203-1243. doi:10.1086/508788.

Du Mont, J., Miller, K., \& Myhr, T. L. (2003). The role of "real rape" and "real victim" stereotypes in the police reporting practices of sexually assaulted women. Violence Against Women, 9, 466-486. doi:10. 1177/1077801202250960.

England, P., Shafer, E. F., \& Fogarty, A. C. (2007). Hooking up and forming romantic relationships on today's college campuses. In M. Kimmel (Ed.), The gendered society reader (pp. 531-547). New York: Oxford University Press.

Estrich, S. (1986). Rape. Yale Law Journal, 95, 1087-1184. doi:10.2307/ 796522.

Feild, H. S. (1978). Attitudes toward rape: A comparative analysis of police, rapists, crisis counselors, and citizens. Journal of Personality and Social Psychology, 36, 156-179. doi:10.1037/ 0022-3514.36.2.156.

Feldman, S. S., Turner, R. A., \& Araujo, K. (1999). Interpersonal context as an influence on sexual timetables of youths: Gender and ethnic effects. Journal of Research on Adolescence, 9, 25-52. doi:10.1207/ s15327795jra0901 2.

Finlay, B. (1985). Right to life vs. the right to die: Some correlates of euthanasia attitudes. Sociology and Social Research, 69, 548-560.

Flores, S. A., \& Hartlaub, M. G. (1998). Reducing rape myth acceptance in male college students: A meta analysis of intervention studies. Journal of College Student Development, 39, 438-448.

Foubert, J. D. (2000). The longitudinal effects of a rape-prevention program on fraternity men's attitudes, behavioral intent, and behavior. Journal of American College Health, 48, 158-163. doi:10.1080/ 07448480009595691.

Foubert, J. D., \& Newberry, J. T. (2006). Effects of two versions of an empathy-based rape prevention program on fraternity men's survivor empathy, attitudes, and behavioral intent to commit rape or sexual assault. Journal of College Student Development, 47, 133-148. doi:10.1353/csd.2006.0016.

Foubert, J. D., Garner, D. N., \& Thaxter, P. J. (2006). An exploration of fraternity culture: Implications for programs to address alcoholrelated sexual assault. College Student Journal, 40, 361-373.

Franiuk, R., Seefelt, J., \& Vandello, J. (2008). Prevalence of rape myths in headlines and their effects on attitudes toward rape. Sex Roles, 58, 790-801. doi:10.1007/s11199-007-9372-4.

Freitas, D. (2008). Sex and the soul: Juggling sexuality, spirituality, romance, and religion on America's college campuses. New York: Oxford University Press.

Freymeyer, R. H. (1997). Rape myths and religiosity. Sociological Spectrum, 17, 473-489. doi:10.1080/02732173.1997.9982179.

Giacopassi, D. J., \& Dull, R. T. (1986). Gender and racial differences in the acceptance of rape myths within a college population. Sex Roles, 15, 63-75. doi:10.1007/BF00287532.

Gilmartin-Zena, P. (1988). Gender differences in students' attitudes toward rape. Sociological Focus, 21, 279-292. doi:10.1080/ 00380237.1988 .10570526 .

Glenn, N., \& Marquardt, E. (2001). Hooking up, hanging out, and hoping for Mr. Right. New York: Institute for American Values.

Graham, K., Bernards, S., Osgood, D. W., Abbey, A., Perks, M., Flynn, A., Dumas, T., \& Wells, S. (2014). 'Blurred lines?' Sexual aggression and barroom culture. Alcoholism: Clinical and Experimental Research, 38, 1416-1424. doi:10.1111/acer.12356.

Gray, N. B., Palileo, G. J., \& Johnson, G. D. (1993). Explaining rape victim blame: A test of attribution theory. Sociological Spectrum, 13, 377-392. doi:10.1080/02732173.1993.9982040. 
Hamilton, L., \& Armstrong, E. A. (2009). Gendered sexuality in young adulthood double binds and flawed options. Gender and Society, 23, 589-616. doi:10.1177/0891243209345829.

Herold, E. S., \& Mewhinney, D. K. (1993). Gender differences in casual sex in aids prevention: A survey of dating bars. Journal of Sex Research, 15, 502-516. doi:10.1080/00224499309551676.

Hertzog, J., \& Yeilding, R. (2009). College women's rape awareness and use of commonly advocated risk reduction strategies. College Student Journal, 43, 59-73.

Hoffman, P. B., \& Hardyman, P. L. (1986). Crime seriousness scales: Public perception and feedback to criminal justice policymaker. Journal of Criminal Justice, 14, 413-431. doi:10.1016/00472352(86)90109-1.

Holman, A., \& Sillars, A. (2012). Talk about 'hooking up': The influence of college student social networks on non-relationship sex. Health Communication, 27, 205-216. doi:10.1080/10410236.2011. 575540.

Hyman, C., \& Handal, P. J. (2006). Definitions and evaluation of religion and spirituality items by religious professionals: A pilot study. Journal of Religion and Health, 45(2), 264-282. doi:10.1007/ s10943-006-9015.

Jozkowski, K. N., \& Peterson, Z. D. (2013). College students and sexual consent: Unique insights. Journal of Sex Research, 50, 517-523. doi:10.1080/00224499.2012.700739.

Kalish, R. (2013). Masculinities and hooking up: Sexual decision-making at college. Culture, Society and Masculinities, 5, 147-165. doi:10. 3149/CSM.0502.147.

Kalof, L. (1993). Rape-supportive attitudes and sexual victimization experiences of sorority and nonsorority women. Sex Roles, 29, 767780. doi:10.1007/BF00289217.

Kennedy, A. M., \& Gorzalka, B. B. (2002). Asian and non-Asian attitudes toward rape, sexual harassment, and sexuality. Sex Roles, 46, 227-238. doi:10.1023/A:1020145815129.

Kimmel, M. (2008). Guyland: The perilous world where boys become men. New York: HarperCollins.

Klaw, E. L., Lonsway, K. A., Berg, D. R., Waldo, C. R., Kothari, C., Mazurek, C. J., et al. (2005). Challenging rape culture. Women and Therapy, 28, 47-63. doi:10.1300/J015v28n02_04.

Lee, J., Pomeroy, E. C., Yoo, S., \& Rheinboldt, K. T. (2005). Attitudes toward rape: A comparison between Asian and caucasian college students. Violence Against Women, 11, 177-196. doi:10.1177/ 1077801204271663.

Lonsway, K. A., \& Fitzgerald, L. F. (1994). Rape myths in review. Psychology of Women Quarterly, 18, 133-164. doi:10.1111/j. 1471-6402.1996.tb00469.x.

LSU Division of Strategic Communications. (2015). Fall facts 2015. Louisiana State University, Office of Budget and Planning, Baton Rouge. Retrieved from http://www.lsu.edu/bgtplan/facts/pdfs/2015fallfacts.pdf.

Markus, H. R., \& Kitayama, S. (1991). Culture and the self: Implications of cognition, emotion, and motivation. Psychological Review, 98, 224-253. doi:10.1037/0033-295X.98.2.224.

Martin, P. Y., \& Hummer, R. A. (1989). Fraternities and rape on campus. Gender and Society, 3, 457-473. doi:10.1177/ 089124389003004004.

McMahon, S. (2010). Rape myth beliefs and bystander attitudes among incoming college students. Journal of American College Health, 59, 3-11. doi:10.1080/07448481.2010.483715.

McMahon, S., \& Farmer, G. L. (2011). An updated measure for assessing subtle rape myths. Social Work Research, 35, 71-81. doi:10.1093/ $\mathrm{swr} / 35.2 .71$.

Melanson, P. K. (1999). Belief in male rape myths: A test of two competing theories (Doctoral dissertation). Retrieved from ProQuest Dissertations \& Theses A \& I. (NQ31935).

Monto, M. A., \& Carey, A. G. (2014). A new standard of sexual behavior? Are claims associated with the "hookup culture" supported by general social survey data? Journal of Sex Research, 51, 605-615. doi:10.1080/00224499.2014.906031.

National Sexual Violence Resource Center (NSVRC). (2015). Statistics about sexual violence. Retrieved from http://www.nsvrc.org/ publications/nsvrc-publications-fact-sheets/media-packet-statisticsabout-sexual-violence.

Nielsen, L. B. (2000). Situating legal consciousness: Experiences and attitudes of ordinary citizens about law and street harassment. Law and Society Review, 34, 1055-1090.

Nielsen, L. B. (2006). License to harass: Law, hierarchy, and offensive public speech. Princeton: Princeton University Press.

Owen, J. J., Rhodes, G. K., Stanley, S. M., \& Fincham, F. D. (2010). 'Hooking up' among college students: Demographic and psychosocial correlates. Archives of Sexual Behavior, 39, 653-663. doi:10. 1007/s10508-008-9414-1.

Page, A. D. (2008). Gateway to reform? Policy implications of police officers' attitudes towards rape. American Journal of Criminal Justice, 33, 44-58. doi:10.1007/s12103-007-9024-9.

Paul, E. L., \& Hayes, K. A. (2002). The casualties of "casual" sex: A qualitative exploration of the phenomenology of college students' hookups. Journal of Social and Personal Relationship, 19, 639661. doi:10.1177/0265407502195006.

Paul, E. L., McManus, B., \& Hayes, A. (2000). Hook-ups': Characteristics and correlates of college students' spontaneous and anonymous sexual experiences. Journal of Sex Research, 37, 76-88. doi:10.1080/00224490009552023.

Payne, D., Lonsway, K., \& Fitzgerald, L. (1999). Rape myth acceptance: Exploration of its structures and its measurement using the Illinois rape myth acceptance scale. Journal of Research in Personality, 33, 27-68. doi:10.1006/jrpe.1998.2238.

Phillips, N. D. (2016). Beyond blurred lines: Rape culture in popular media. Lanham: Rowman \& Littlefield Publishers.

Reid, J. A., Elliott, S., \& Webber, G. R. (2011). Casual hookups to formal dates refining the boundaries of the sexual double standard. Gender and Society, 25, 545-568. doi:10.1177/0891243211418642.

Robinson, D. T., Gibson-Beverly, G., \& Schwartz, J. P. (2004). Sorority and fraternity membership and religious behaviors: Relation to gender attitudes. Sex Roles, 50, 871-877. doi:10.1023/B:SERS. 0000029104.87813.d5.

Ronen, S. (2010). Grinding on the dance floor gendered scripts and sexualized dancing at college parties. Gender and Society, 24, 355-377. doi: $10.1177 / 0891243210369894$.

Rupp, L. J., Taylor, V., Regey-Messalem, S., Fogarty, A., \& England, P. (2013). Queer women in the hookup scene: Beyond the closet? Gender and Society, 28, 212-235. doi:10.1177/0891243213510782.

Sable, M. R., Danis, F., Mauzy, D. L., \& Gallagher, S. K. (2006). Barriers to reporting sexual assault for women and men: Perspectives of college students. Journal of American College Health, 55, $157-$ 162. doi:10.3200/JACH.55.3.157-162.

Sapp, M., Farrell Jr., W. C., Johnson Jr., J. H., \& Hitchcock, K. (1999). Attitudes toward rape among African American male and female college students. Journal of Couseling and Development, 77, 204 208. doi:10.1002/j.1556-6676.1999.tb02441.x.

Schwartz, M. D., DeKeseredy, W. S., Tait, D., \& Alvi, S. (2001). Male peer support and a feminist routine activities theory: Understanding sexual assault on the college campus. Justice Quarterly, 18, 623649. doi:10.1080/07418820100095041.

Scott-Sheldon, L. A., Carey, K. B., \& Carey, M. P. (2008). Health behavior and college students: Does greek affiliation matter? Journal of Behavioral Medicine, 31, 61-70. doi:10.1007/s10865-007-9136-1.

Scully, D., \& Marolla, J. (1985). "Riding the bull at Gilley's": Convicted rapists describe the rewards of rape. Social Problems, 32, 251-263. doi: $10.2307 / 800685$.

Sleath, E., \& Bull, R. (2012). Comparing rape victim and perpetrator blaming in a police officer sample: Differences between police 
officers with and without special training. Criminal Justice and Behavior, 39, 642-661. doi:10.1177/0093854811434696.

Stinson, R. D. (2010). Hooking up in young adulthood: A review of factors influecing the sexual behavior of college students. Journal of College Student Psychotherapy, 24, 98-115. doi:10.1080/ 87568220903558596.

Sweeney, B. (2014a). Masculine status, sexual performance, and the sexual stigmatization of Women. Symbolic Interaction, 37(3), 369-390. doi:10.1002/symb.113.

Sweeney, B. (2014b). To sexually perform or protect: Masculine identity construction and perceptions of women's sexuality on a university campus in the midwestern USA. Gender, Place and Culture, 21, 1108-1124. doi:10.1080/0966369X.2013.817968.

Tinkler, J. E. (2008). "People are too quick to take offense": The effects of legal information and beliefs on definitions of sexual harassment. Law and Social Inquiry, 33, 417-445. doi:10.1111/j.1747-4469. 2008.00108.x.

Tinkler, J. E., Becker, S., \& Clayton, K. A. (2016). "Kind of natural, kind of wrong": Young people's beliefs about the morality, legality, and normalcy of sexual aggression in public drinking settings. Law and Social Inquiry. doi:10.1111/1si.12235.

Uecker, J. E. (2008). Religion, pledging, and the premarital sexual behavior of married young adults. Journal of Marriage and Family, 70, 728-744. doi:10.1111/j.1741-3737.2008.00517.x.

Vonderhaar, R. L., \& Carmody, D. C. (2015). There are no "innocent victims": The influence of just world beliefs and prior victimization of rape myth acceptance. Journal of Interpersonal Violence, 30, 1615-1632. doi:10.1177/0886260514549196.

Wade, L. (2017). American hookup: The new culture of sex on campus. New York: W.W. Norton \& Co..

Ward, C. A. (1995). Attitudes toward rape: Feminist and social psychological perspectives. London: SAGE.

Ward, S. K., Chapman, K., Cohn, E., White, S., \& Williams, K. (1991). Acquaintance rape and the college social scene. Family Relations, 40, 65-71.

Weinberg, M. S., \& Williams, C. J. (1988). Black sexuality: A test of two theories. Journal of Sex Research, 25, 197-218. doi:10.1080/ 00224498809551455.

Wilkins, A. C. (2012). Stigma and status interracial intimacy and intersectional identities among Black college men. Gender and Society, 26, 165-189. doi: 10.1177/0891243211434613.

Wilson, L. C., \& Miller, K. E. (2016). Meta-analysis of the prevalence of unacknowledged rape. Trauma, Violence \& Abuse, 17, 149-159. doi:10.1177/1524838015576391.

Wylie, L., \& Forest, J. (1992). Religious fundamentalism, right-wing authoritarianism and prejudice. Psychological Reports, 7, 12911298. doi:10.2466/pr0.1992.71.3f.1291.

Zullig, K. J., Ward, R. M., \& Horne, T. (2006). The association between perceived spirituality, religiosity, and life satisfaction: The mediating role of self-rated health. Social Indicators Research, 79, 225-274. doi:10.1007/s11205-005-4127-5. 